\title{
ARTICLES
}

\section{Endothelin-1 Inhibits Apoptosis of Pulmonary Arterial Smooth Muscle in the Neonatal Rat}

\author{
ROBERT P. JANKOV, CRYSTAL KANTORES, ROSETTA BELCASTRO, MAN YI, AND A. KEITH TANSWELL
}

\begin{abstract}
Clinical Integrative Biology [R.P.J., C.K.], Sunnybrook Research Institute; Lung Biology Programme [R.B., M.Y., A.K.T.], The Hospital for Sick Children Research Institute; the Departments of Paediatrics [R.P.J., A.K.T.] and Physiology [A.K.T.], University of Toronto,
\end{abstract} Toronto, Ontario M5S 1A8, Canada

\begin{abstract}
Vascular wall remodeling in pulmonary hypertension is contributed to by an aberration in the normal balance between proliferation and apoptosis of smooth muscle. We observed that endothelin (ET)-1 is a critical mediator of vascular remodeling in neonatal rats chronically exposed to $60 \% \mathrm{O}_{2}$, but has no direct proliferative effects on cultured neonatal rat pulmonary artery smooth muscle cells (PASMCs). These findings led us to hypothesize that ET-1 may modulate remodeling by inhibiting apoptosis of smooth muscle. ET-1 $(0.1 \mu \mathrm{M})$ was found to significantly attenuate both Paclitaxel- and serum deprivation-induced PASMC apoptosis, likely through stimulation of the $\mathrm{ET}_{\mathrm{A}}$ receptor $\left(\mathrm{ET}_{\mathrm{A}} \mathrm{R}\right)$. ET-1 also prevented Paclitaxel-induced up-regulation of pro-apoptotic Bax and cleaved (activated) caspase-3. In rat pups exposed from birth to $60 \%$ $\mathrm{O}_{2}$ for $7 \mathrm{~d}$, arterial wall expression of Bax was decreased and expression of both $\mathrm{ET}_{\mathrm{A}} \mathrm{R}$ and anti-apoptotic $\mathrm{Bcl}$-xL were increased. Furthermore, increased numbers of TUNEL-positive cells were evident in the walls of pulmonary arteries from $60 \% \mathrm{O}_{2}$-exposed animals treated with a combined ET receptor antagonist, SB217242, relative to air-exposed and vehicle-treated groups. Together, these findings suggest that ET-1 mediates remodeling of neonatal rat pulmonary arteries by inhibiting smooth muscle apoptosis. (Pediatr Res 60: 245-251, 2006)
\end{abstract}

$\mathrm{P}$ ulmonary hypertension is a frequently observed complication of critically ill newborn infants that causes considerable mortality and long-term morbidity (1). The pathogenesis of pulmonary hypertension is believed to relate to two phenomena that contribute to increased pulmonary arterial resistance and pressure: sustained vasoconstriction and remodeling of resistance arteries. Arterial wall remodeling is contributed to, in major part, by hyperplasia of the medial smooth muscle layer (2). Remodeling increases vascular re-

Received January 11, 2006; accepted April 26, 2006

Correspondence: Robert P. Jankov, M.D., Ph.D., Department of Newborn and Developmental Paediatrics, Sunnybrook Health Sciences Centre, 76 Grenville Street, Toronto, Ontario M5S 1B2, Canada; e-mail: robert.jankov@sunnybrook.ca

Supported by Operating (R.P.J.) and Group (A.K.T.) grants from the Canadian Institutes of Health Research (CIHR) and a grant-in-aid from the Physicians' Services Incorporated Foundation (R.P.J.). R.P.J. is supported by a Career Development Award from the Canadian Child Health Clinician Scientist Program, a CIHR Strategic Training Program. A.K.T. holds the Hospital for Sick Children Women's Auxiliary Chair in Neonatal Medicine.

DOI: 10.1203/01.pdr.0000233056.37254.0b sistance through luminal encroachment and enhanced contractile potential $(3,4)$, which limits the effectiveness of established vasodilator therapies. Moreover, given that alveolar and vascular development appear to be interdependent processes, pulmonary hypertension in the newborn may also be associated with inhibition of lung growth and alveolar development $(5,6)$. A greater understanding of the mechanisms leading to pulmonary vascular remodeling in the newborn therefore has the potential to greatly improve outcomes.

An aberration in the normal balance between proliferation and apoptosis of smooth muscle contributes to vascular remodeling in pulmonary hypertension (7-9). Studies utilizing various endothelin (ET) receptor antagonists have confirmed that the polypeptide, ET-1, is critical to the pathogenesis of vascular remodeling in both adult and newborn $(10,11)$ rodent models of chronic pulmonary hypertension. A major role for ET-1 in pulmonary hypertension of human newborns is also suggested by observational studies $(12,13)$. In addition to being the most potent vasoconstrictor described to date, ET-1 has been reported to directly modulate growth in vascular smooth muscle cells (SMCs) derived from adult humans (14) and rats (15) by acting as an autocrine/paracrine mitogen. ET-1 has also been described to have anti-apoptotic effects on vascular cells derived from adult animals, including endothelial cells (16), fibroblasts (17) and systemic SMCs (18). Compared with adults, however, there is a paucity of information on the mechanisms by which ET-1 modulates smooth muscle remodeling in the newborn period. Direct extrapolation from adult studies may not be valid, as major differences between immature and mature animals have been reported in

\footnotetext{
Abbreviations: Bax, Bcl-2-associated $\mathrm{X}$ protein; BrdU, bromodeoxyuridine; DAPI, 4' , 6-diamidino-2' -phenylindole; ET, endothelin; $\mathbf{E T}_{\mathbf{A}} \mathbf{R}$, endothelin A receptor; $\mathbf{E T}_{\mathbf{B}} \mathbf{R}$, endothelin B receptor; FBS, fetal bovine serum; GAPDH, glyceraldehyde- $3^{\prime}$-phosphate dehydrogenase; PASMC, pulmonary artery smooth muscle cell; SMC, smooth muscle cell
} 
the functional (4) and growth (19) responses of both normal and injured pulmonary vascular smooth muscle.

We have previously observed that expression of ET-1 was greatly increased in the lungs of newborn rats exposed to $60 \%$ $\mathrm{O}_{2}$ from birth (20), a model for newborn pulmonary hypertension with vascular remodeling (21). Increased ET-1 was critical to the development of remodeling, in that right ventricular hypertrophy and arterial medial wall thickening, induced by exposure to $60 \% \mathrm{O}_{2}$ for $14 \mathrm{~d}$, were completely attenuated by treatment with a combined ETA $\left(\mathrm{ET}_{\mathrm{A}} \mathrm{R}\right) / \mathrm{ETB}$ $\left(\mathrm{ET}_{\mathrm{B}} \mathrm{R}\right)$ receptor antagonist, SB217242 (Enrasentan) (10). We have recently reported in this model that significantly increased pulmonary arterial smooth muscle proliferation was evident after exposure to $60 \% \mathrm{O}_{2}$ for $7 \mathrm{~d}$ (22). Our aim in this study was to examine the effects of ET-1 on pulmonary arterial smooth muscle proliferation and apoptosis in vitro and the effects of ET receptor blockade on these parameters in the $60 \% \mathrm{O}_{2}$ exposure model. Our findings reported herein suggest that ET-1 has important anti-apoptotic effects on newborn rat pulmonary arterial smooth muscle, which may contribute significantly to vascular remodeling.

\section{METHODS}

Materials. SB217242 (Enrasentan) was a generous gift from Dr. Douglas Hay (Glaxo SmithKline, King of Prussia, PA). $\left[{ }^{3} \mathrm{H}\right]$ Thymidine, $\left[8-{ }^{14} \mathrm{C}\right] \mathrm{ade}-$ nine and ET-1 were from ICN Biomedicals (Costa Mesa, CA). Paclitaxel (Taxol®), BQ-123 and BQ-788 were from Alexis Biochemicals (San Diego, CA). In situ TUNEL kits and Cell Death Detection ELISA ${ }^{\text {PLUS }}$ kits were from Roche (Laval, QC, Canada). Anti-glyceraldehyde-3'-phosphate dehydrogenase (GAPDH), anti-cleaved caspase-3, anti-Bcl-xL and biotin-conjugated secondary antibodies were from Santa Cruz Biotechnology (Santa Cruz, CA). Anti-ET-1 was from Peninsula Laboratories (San Carlos, CA). Anti-Bcl-2associated X protein (Bax), bromodeoxyuridine (BrdU) and an anti-BrdU MAb were from $\mathrm{BD}$ Pharmingen (Mississauga, Canada). Anti-ET $\mathrm{A}$, and blocking peptide were from IBL Inc. (Gumma, Japan). Peroxidase-conjugated secondary antibodies were from Cell Signaling Technology (Beverly, MA). Fluoresceinand Alexa® 546-conjugated secondary antibodies were from Calbiochem (San Diego, CA) and Invitrogen (Burlington, Canada), respectively.

Institutional review. All procedures involving animals were conducted according to criteria established by the Canadian Council on Animal Care. Approval for the studies was obtained from the Animal Care Committees of the Sunnybrook and the Hospital for Sick Children Research Institutes.

Oxygen exposure system and intervention. On the anticipated day of delivery, pathogen-free timed pregnant Sprague-Dawley rats were placed in Plexiglas chambers with gas delivery automatically adjusted to maintain an $\mathrm{O}_{2}$ concentration within $0.1 \%$ of the set point (OxyCycler A84XOV, Redfield, NY). Experiments were conducted as paired exposures with one chamber receiving $60 \% \mathrm{O}_{2}$ and the other receiving air $\left(21 \% \mathrm{O}_{2}\right)$ for $7 \mathrm{~d}$. Equal litter sizes (10-12 pups) were maintained to control for nutritional effects and dams were exchanged daily between paired chambers to prevent maternal $\mathrm{O}_{2}$ toxicity. Pups received daily i.p. injections of SB217242 in vehicle or vehicle alone as previously described $(10,22)$. At the termination of each exposure period, pups were either killed by pentobarbital overdose or exsanguination after anesthesia. For some experiments, pups received $20 \mathrm{mg} / \mathrm{kg}$ BrdU i.p. $2 \mathrm{~h}$ before sacrifice.

PASMC culture. PASMCs were isolated by an explant technique using pooled pulmonary arteries from infant rats, as previously described (22). All experiments were performed using cells from the first or second passage. Cells were routinely maintained in DMEM with $10 \%$ (vol/vol) fetal bovine serum (FBS) and antibiotic-antimycotic solution at a gas phase of $21 \% \mathrm{O}_{2}$, $5 \% \mathrm{CO}_{2}$ and $74 \% \mathrm{~N}_{2}$. Cells were passaged using $0.05 \%$ (wt/vol) trypsin/ EDTA followed by centrifugation at $300 \times g$ for $5 \mathrm{~min}$ and seeded at a density of $10^{5}$ cells $/ \mathrm{mL}$ then allowed to attach and grow to subconfluence for $48-72$ $\mathrm{h}$ in DMEM with $10 \%$ (vol/vol) FBS.

Measurement of PASMC proliferation. Rates of DNA synthesis were assessed by determination of $\left[{ }^{3} \mathrm{H}\right]$ thymidine incorporation into cellular DNA as previously described (23). Following $48 \mathrm{~h}$ of serum starvation (in $0.1 \%$ (vol/vol) FBS) to render the PASMCs quiescent, cells were treated with 1 $\mu \mathrm{Ci} / \mathrm{mL}\left[{ }^{3} \mathrm{H}\right]$ thymidine in DMEM (control) or in DMEM containing ET-1 $(0.01-10 \mu \mathrm{M})$. Cells were then incubated for $24 \mathrm{~h}$ or $7 \mathrm{~d}$ at a gas phase of $21 \%$ $\mathrm{O}_{2} / 5 \% \quad \mathrm{CO}_{2} / 74 \% \quad \mathrm{~N}_{2}$ (normoxia) or $50 \% \quad \mathrm{O}_{2} / 5 \% \quad \mathrm{CO}_{2} / 45 \% \mathrm{~N}_{2}$ (hyperoxia). Recognizing that the $\mathrm{pO}_{2}$ in pulmonary arteries is somewhat less than in the post-alveolar vasculature, we arbitrarily chose an $\mathrm{O}_{2}$ concentration of $50 \%$ to simulate the influence of $60 \% \mathrm{O}_{2}$ in vivo. Results are expressed as a percentage of control (DMEM only) values for dpm/well.

Measurement of PASMC toxicity. Toxicity to PASMCs was assessed by measurement of the release of pre-incorporated $\left[8{ }^{14} \mathrm{C}\right]$ adenine into culture medium, as previously described for other cell types (24). PASMCs were grown to subconfluence and serum starved, as described above, and incubated with $0.2 \mu \mathrm{Ci} / \mathrm{mL}\left[8{ }^{14} \mathrm{C}\right]$ adenine for $2 \mathrm{~h}$ to achieve intracellular incorporation of $\left[8-{ }^{14} \mathrm{C}\right]$ adenine. PASMCs were then exposed to DMEM alone (control) or DMEM containing ET-1 as described above. Results are presented as a cytotoxicity index where the percentage of $\left[8-{ }^{14} \mathrm{C}\right] \mathrm{adenine}$ release has been standardized to the mean percentage release by control cells that was assigned a value of 1 , and all other values expressed as a multiple or fraction of the control value.

Fluorescent immunocytochemistry. PASMCs were fixed with ice-cold $4 \%$ (wt/vol) paraformaldehyde for 5 min and permeabilized with $1 \times$ PBS containing $0.2 \%$ (vol/ $/ \mathrm{vol}$ ) Triton-X and $1 \%(\mathrm{wt} / \mathrm{vol}$ ) BSA for $5 \mathrm{~min}$ at room temperature. After washing in $1 \times \mathrm{PBS}$, sections were blocked with $1 \%$ (wt $/ \mathrm{vol}$ ) BSA $/ 5 \%$ (vol/vol) normal goat or donkey serum for $1 \mathrm{~h}$ followed by overnight incubation at $4^{\circ} \mathrm{C}$ with anti-Bax antibody (diluted 1:1000 $=1$ $\mu \mathrm{g} / \mathrm{mL}$ ) or anti-cleaved caspase-3 (diluted 1:100 $=2 \mu \mathrm{g} / \mathrm{mL}$ ). Sections were incubated with fluorescein- or Alexa ${ }^{\circledR}$ 546-conjugated secondary antibody diluted to $1: 300$ at room temperature in the dark for $2 \mathrm{~h}$, then washed and aqueous mounted with DAPI. Images were digitally captured with a Penguin 600CL digital camera and Viewfinder capture software (Pixera Corp., Los Gatos, CA) using an epifluorescent microscope (Axioskop, Carl Zeiss Inc., Oberkochen, Germany) with appropriate filter sets.

Examination of apoptosis. PASMCs were treated with DMEM alone (control), or DMEM with the apoptosis-inducer, Paclitaxel $(10 \mu \mathrm{M})$, ET-1 $(0.1 \mu \mathrm{M})$, both Paclitaxel and ET-1 or the ET receptor antagonists, BQ-123 $\left(\mathrm{ET}_{\mathrm{A}} \mathrm{R}\right.$-specific; $\left.1 \mu \mathrm{M}\right)$, or BQ-788 $\left(\mathrm{ET}_{\mathrm{B}} \mathrm{R}\right.$-specific; $\left.1 \mu \mathrm{M}\right)$ for $24 \mathrm{~h}$ at a gas phase of $21 \% \mathrm{O}_{2} / 5 \% \mathrm{CO}_{2} / 74 \% \mathrm{~N}_{2}$. PASMCs or frozen lung tissue sections, prepared as previously described (22), were stained using a fluorescein TUNEL enzymatic labeling assay kit (Roche), according to the manufacturer's instructions. Positive controls were generated by incubation with DNAse $\mathrm{I}(3 \mathrm{U} / \mathrm{mL})$ for $10 \mathrm{~min}$ before labeling. Apoptosis was quantified by measuring histone-complexed DNA fragments, using a commercially available colorimetric ELISA kit (Roche), according to the manufacturer's instructions. Values are expressed as an apoptosis index, where the mean OD change in control cells was assigned a value of 1 , and all other values expressed as a multiple or fraction of the control value.

Immunohistochemistry. Paraffin-embedded lung tissue sections were prepared and immunostained as previously described (20). For $\mathrm{ET}_{\mathrm{A}} \mathrm{R}$, sections were incubated with $0.6 \mathrm{mg} / \mathrm{mL}$ trypsin in $1 \times$ PBS for $20 \mathrm{~min}$ at room temperature for antigen retrieval. Concentrations of the primary antisera were: $1 / 200(1 \mu \mathrm{g} / \mathrm{mL})$ for ET-1, $1 / 20(5 \mu \mathrm{g} / \mathrm{mL})$ for $\mathrm{ET}_{\mathrm{A}} \mathrm{R}, 1 / 1000(1 \mu \mathrm{g} / \mathrm{mL})$ for Bax, $1 / 80(2.5 \mu \mathrm{g} / \mathrm{mL})$ for Bcl-xL and $1 / 200$ for secondary antibodies. Negative controls were generated by omission of the primary antibody except for anti-ET $\mathrm{A}_{\mathrm{A}} \mathrm{f}$ for which blocking peptide was used. Acetone-fixed frozen lung sections were immunostained for $\operatorname{BrdU}(1 / 100=10 \mu \mathrm{g} / \mathrm{mL})$, as previously described (22).

Western blot analyses. Western blot analyses on total lung (pooled from 2 animals from each of 4 separate litters) were performed as previously described (22). Concentration of primary antisera were $1 / 4000(0.25 \mu \mathrm{g} / \mathrm{mL})$ for Bax and1/1000 $(0.2 \mu \mathrm{g} / \mathrm{mL})$ for GAPDH. Protein bands were imaged using an enhanced chemiluminescence reagent (Pierce Biotechnology, Rockford, IL) and exposure to blue film (CL-XPosure, Pierce Biotechnology). Bands were quantified by digital densitometry of non-saturated radiographs with the background density removed (ImageJ Version 1.30, National Institutes of Health, Bethesda, MD). Differences in protein loading were accounted for by normalizing results to GAPDH.

Data presentation and analysis. Unless otherwise stated, values are expressed as the mean \pm SEM from 4 wells or litters. For in vitro studies, at least one replicate from a different litter was performed to ensure reproducibility of results. Statistical significance $(p<0.05)$ was determined by one-way ANOVA followed by pair-wise multiple comparisons using the Tukey test.

\section{RESULTS}

ET-1 is a survival factor, but not a mitogen, for infant rat PASMCs Treatment of PASMCs with ET-1 did not stimulate PASMC proliferation, as measured by thymidine uptake into 
DNA (Figs. $1 A, B$ ), nor did it cause toxicity at any of the concentrations tested (Fig. 1C,D). These negative findings were consistent whether cells were treated in $21 \% \mathrm{O}_{2}$ (Normoxia; Fig. $1 A, C$ ) or $50 \% \mathrm{O}_{2}$ (Hyperoxia; Fig. $1 B, D$ ) or for a more prolonged period of $7 \mathrm{~d}$ in either $\mathrm{O}_{2}$ concentration $(p>$ 0.05 , compared with control; data not shown). Moreover, ET-1 $(0.1 \mu \mathrm{M})$ did not augment the mitogenic effects of PDGF-BB on infant rat PASMCs (22) $(p>0.05$ compared with $20 \mu \mathrm{g} / \mathrm{mL}$ PDGF-BB alone; data not shown), regardless of treatment duration or $\mathrm{O}_{2}$ concentration. ET-1 was found to significantly decrease basal levels of cell death at certain concentrations (Fig. 1C,D), consistent with a protective effect on cell survival.

ET-1 inhibits PASMC apoptosis. Fluorescein-labeled TUNEL staining, as a marker of PASMC apoptosis, is shown in Fig. 2. Compared with control PASMCs, Paclitaxel (10 $\mu \mathrm{M})$ caused a marked increase in TUNEL-positive cells, which was almost completely attenuated by ET-1 $(0.1 \mu \mathrm{M})$. Blockade of the $\mathrm{ET}_{\mathrm{A}} \mathrm{R}$ with BQ-123 (1 $\mu \mathrm{M}$; Fig. 2) also increased apoptosis, an effect which was not observed with the $\mathrm{ET}_{\mathrm{B}} \mathrm{R}$ blocker, BQ-788 $(1 \mu \mathrm{M})$, suggesting that the inhibitory effects of ET-1 on apoptosis resulted from $\mathrm{ET}_{\mathrm{A}} \mathrm{R}$ stimulation. Measurement of histone-associated DNA fragments, as a quantitative index of apoptosis, is shown in Fig. 3. Compared with control PASMCs, Paclitaxel induced a more than 12-fold increase over basal levels of apoptosis. Apoptosis induced by serum starvation, or by the addition of Paclitaxel, were both significantly $(p<0.01)$ attenuated by ET-1 (Fig. 3).

ET-1 attenuates increased Bax expression and activation of caspase-3 induced by paclitaxel. Cytochemistry for immunoreactive Bax, a key pro-apoptotic protein, and activated caspase-3, a final effector of apoptosis, are shown in Fig. 4. Compared with control and ET-1 treated cells, in which minimal Bax and activated caspase-3 immunoreactivity were
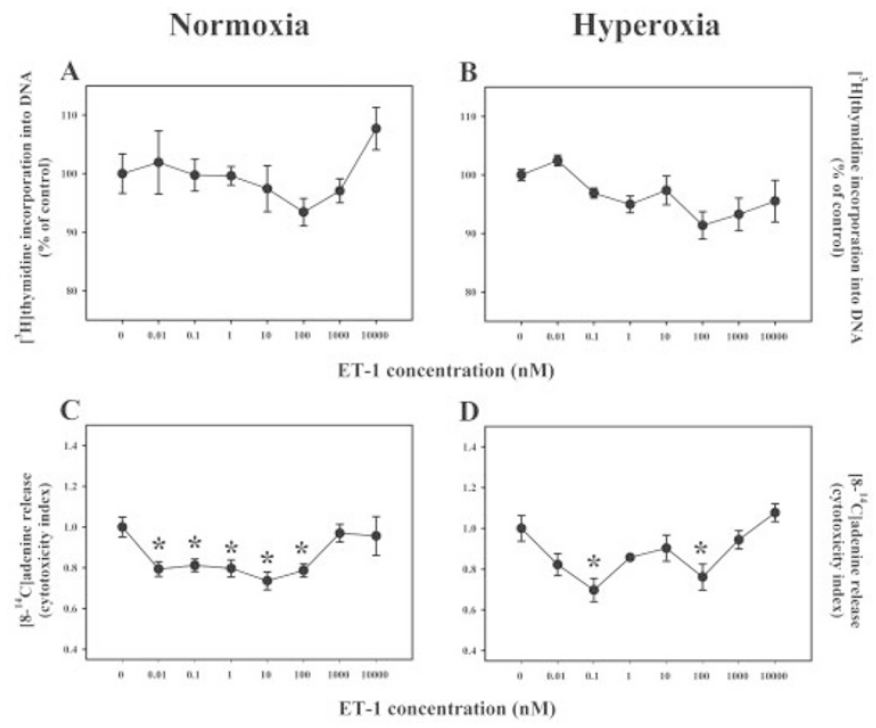

Figure 1. ET-1 is a survival factor, but not a mitogen, for infant rat PASMCs. Proliferation $(A, B)$ or cytotoxicity $(C, D)$ in response to a range of concentrations of ET-1, expressed as a percentage or fraction of the control (0) value. $* p<0.01$, by ANOVA, compared with control. Experiments were either carried out in $21 \% \mathrm{O}_{2}$ (Normoxia; A, C) or $50 \% \mathrm{O}_{2}$ (Hyperoxia; B, D)
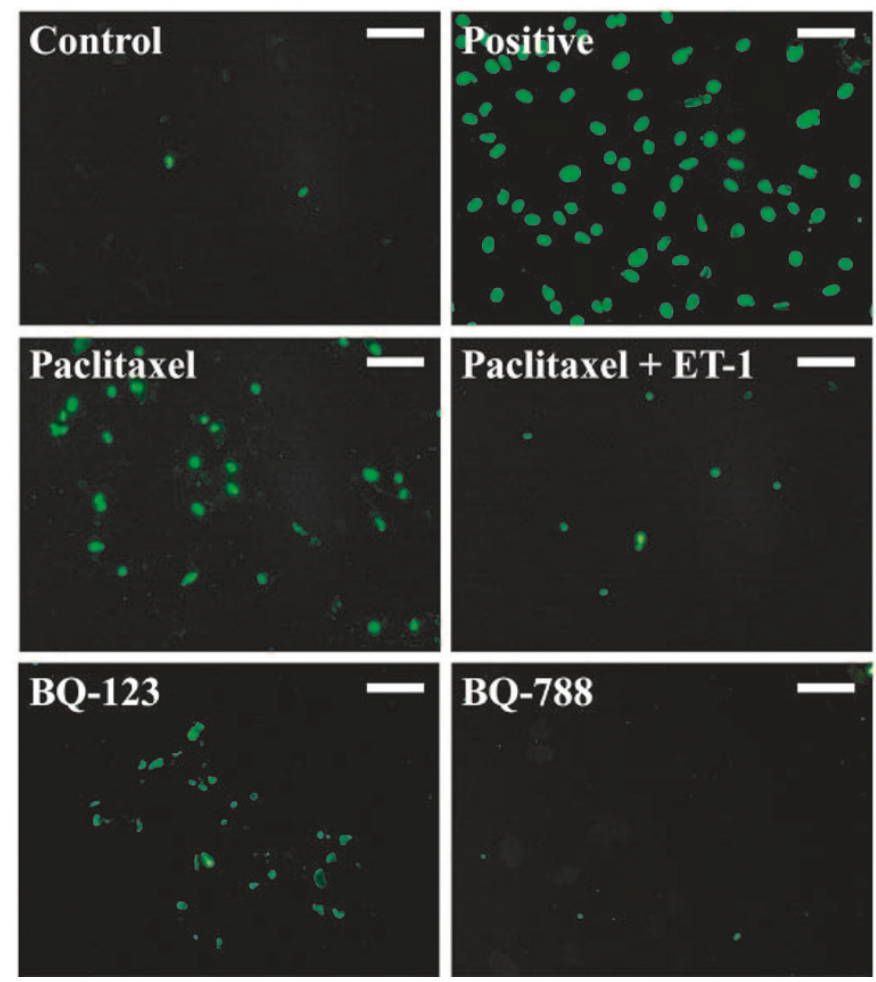

Figure 2. ET-1 inhibits PASMC apoptosis. Representative images of TUNEL-positive nuclei (green fluorescence) in PASMCs exposed to $0.1 \%$ serum (Control), Paclitaxel, Paclitaxel and ET-1 combined (Paclitaxel + ET-1), or an $\mathrm{ET}_{\mathrm{A}} \mathrm{R}$ (BQ-123) or $\mathrm{ET}_{\mathrm{B}} \mathrm{R}$ antagonist (BQ-788). Bar lengths = $100 \mu \mathrm{m}$. A positive control (Positive) demonstrates semi-confluence of cells.

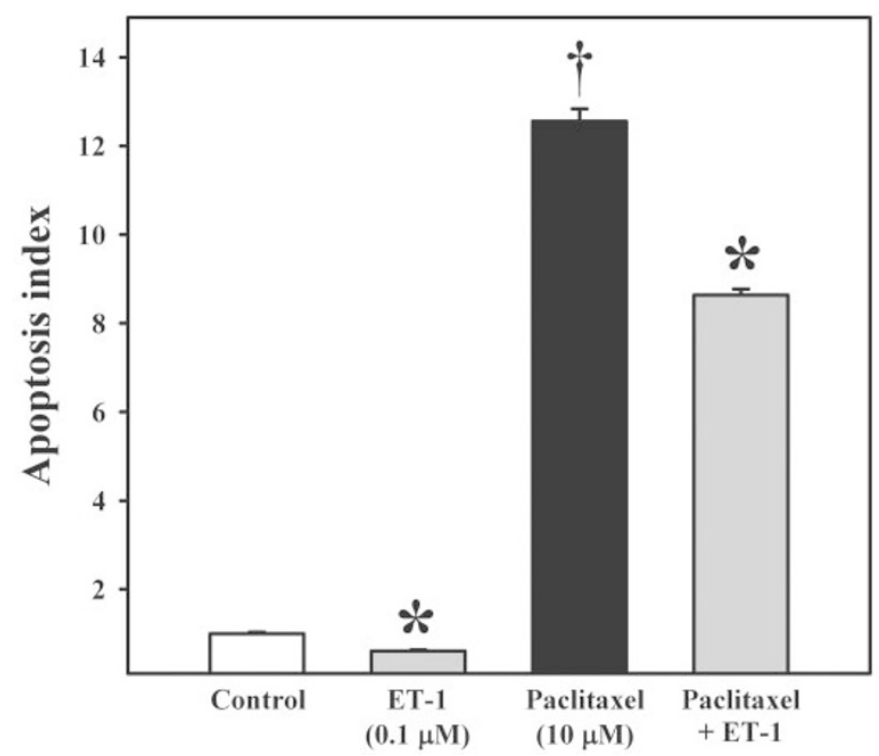

Figure 3. ET-1 inhibits PASMC apoptosis. PASMCs were exposed to medium without serum or other additives (Control), or medium with ET-1, Paclitaxel, or Paclitaxel and ET-1 combined (Paclitaxel + ET-1). Values represent mean \pm SEM of six wells/group. $* p<0.01$, by ANOVA, compared with control values. ${ }^{\dagger} p<0.01$, by ANOVA, compared with all other groups.

evident, treatment with Paclitaxel greatly increased the immunoreactivity of both proteins, which was attenuated by coaddition of ET-1. 
Bax

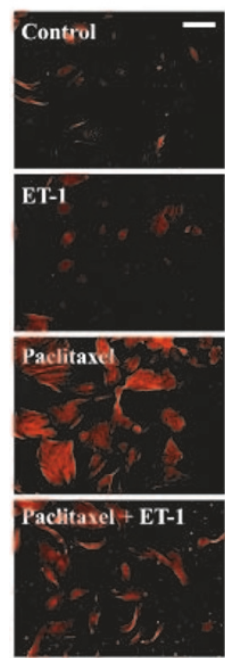

Cleaved Caspase-3

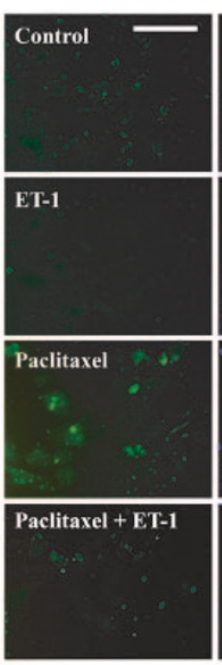

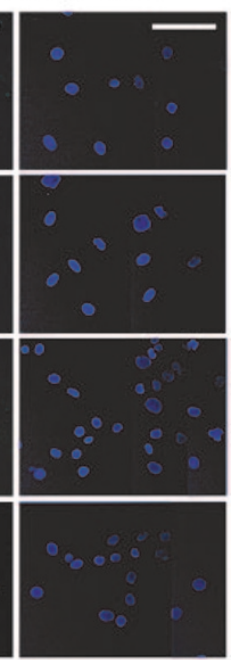

Figure 4. ET-1 attenuates increased Bax expression and activation of caspase-3 induced by Paclitaxel. Representative images of Bax immunocytostaining (left panels; red fluorescence) and activated caspase-3 (right panels; green fluorescence) and their corresponding images showing DAPI-stained nuclei (violet fluorecence) on PASMCs exposed to $0.1 \%$ serum (Control), ET-1, Paclitaxel, or Paclitaxel and ET-1 combined (Paclitaxel + ET-1). Bar lengths $=100 \mu \mathrm{m}$.

Exposure to $60 \% \mathrm{O}_{2}$ increases $\mathrm{ET}-1$ and $\mathrm{ET}_{A} \mathrm{R}$ expression. Changes in expression of ET-1 (Fig. 5A-D) and $\mathrm{ET}_{\mathrm{A}} \mathrm{R}$ (Fig. $5 E-H$ ) were examined by immunohistochemistry. Exposure to $60 \% \mathrm{O}_{2}$ for $7 \mathrm{~d}$ markedly increased the expression of ET-1 in the lung and $\mathrm{ET}_{\mathrm{A}} \mathrm{R}$ on the medial walls of pulmonary resistance arteries, relative to animals exposed to air. Pups treated with SB217242 had increased $\mathrm{ET}_{\mathrm{A}} \mathrm{R}$ expression on the vascular wall, similar to vehicle-treated $60 \% \mathrm{O}_{2}$-exposed pups, whether exposed to air or $60 \% \mathrm{O}_{2}$.

SB217242 increases smooth muscle apoptosis in 60\% $\mathrm{O}_{2}$-exposed animals. Changes in vascular wall apoptosis on frozen lung tissue sections, using TUNEL staining as a marker, are shown in Fig. 6. There were few vascular wall nuclei that labeled TUNEL-positive in vehicle-treated animals exposed to either air or $60 \% \mathrm{O}_{2}$ or air-exposed animals treated with SB217242. In contrast, animals exposed to $60 \% \mathrm{O}_{2}$ and treated with SB217242 had numerous TUNEL-positive nuclei evident on the medial walls of pulmonary resistance arteries.

SB217242 prevents increased smooth muscle proliferation in 60\% $\mathrm{O}_{2}$-exposed animals. Staining of frozen lung sections for proliferating cells within the vascular wall, using immunoreactive BrdU uptake as a marker, is shown in Fig. 7. Compared with air-exposed animals, pups treated with vehicle and exposed to $60 \% \mathrm{O}_{2}$ had greatly increased numbers of positive nuclei in the medial walls of pulmonary arteries. This $\mathrm{O}_{2}$-induced increased was completely inhibited by treatment with SB217242.

Exposure to 60\% $\mathrm{O}_{2}$ decreases Bax and increases $\mathrm{Bcl}-\mathrm{xL}$ expression. Changes in arterial wall and total lung expression of pro-apoptotic Bax (Fig. 8) and anti-apoptotic Bcl-xL (Fig. 9) induced by exposure to $60 \% \mathrm{O}_{2}$, and the effects of treatment with SB217242, were examined by immunohistochemistry (Figs. 8 and 9) and Western blot analyses (Fig. 8). Compared

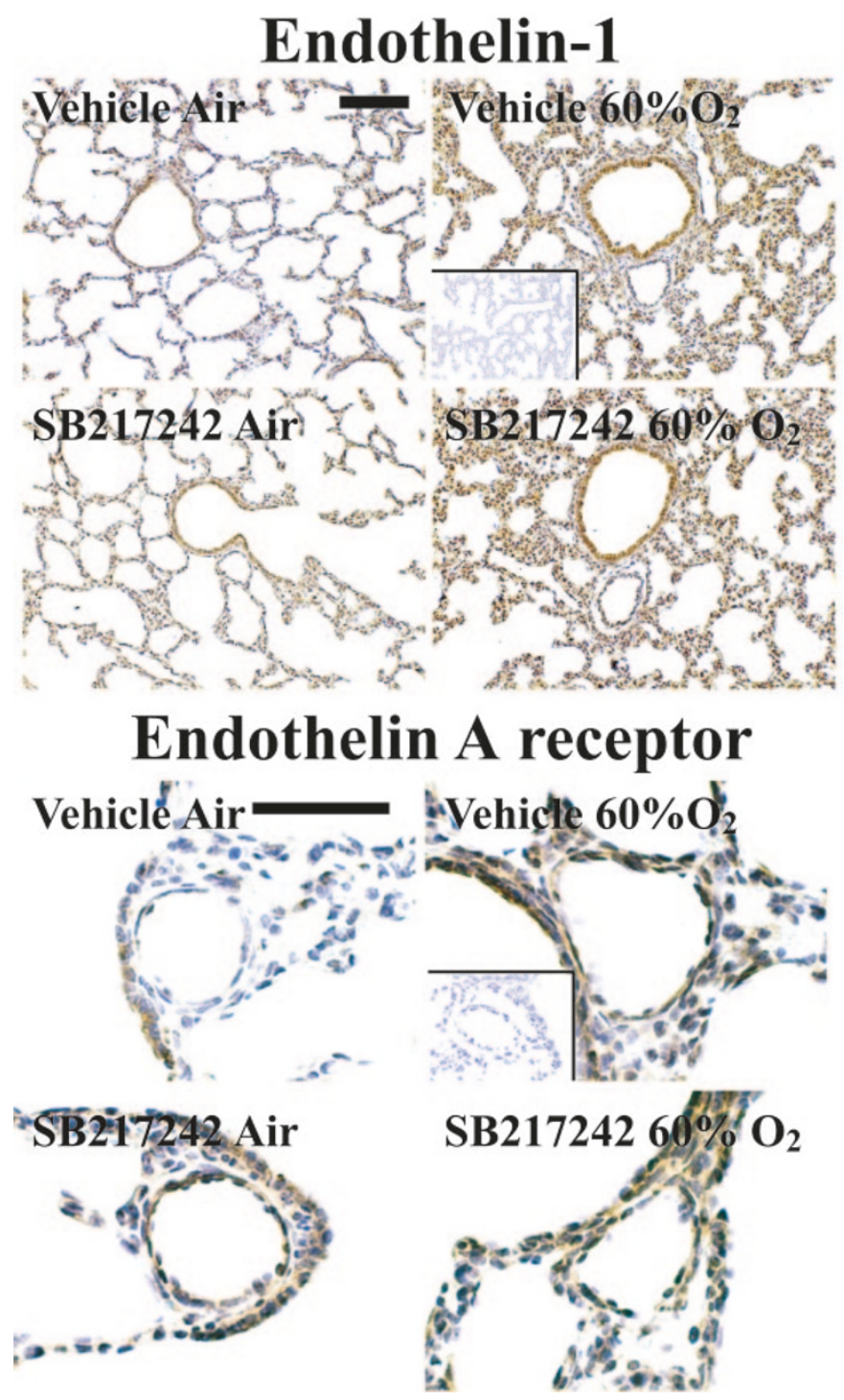

Figure 5. Exposure to $60 \% \mathrm{O}_{2}$ increases ET-1 and $\mathrm{ET}_{\mathrm{A}} \mathrm{R}$ expression. Representative photomicrographs of immunoreactive ET-1 or $\mathrm{ET}_{\mathrm{A}} \mathrm{R}$ (brown stain) in rat pups exposed from birth to either air or $60 \% \mathrm{O}_{2}$ and receiving either vehicle or SB217242. Bar lengths $=50 \mu \mathrm{m}$. Insets: negative controls demonstrating complete lack of staining.

with air-exposed vehicle-treated animals where immunoreactive Bax was predominantly detected on bronchial epithelium and pulmonary resistance arteries, exposure to $60 \% \mathrm{O}_{2}$ caused a marked overall decrease in immunoreactivity in these sites (Fig. 8), a finding which was confirmed by quantification in the total lung (Fig. 8) and which was completely reversed by treatment with SB217242. In contrast, expression of Bcl-xL, was increased by exposure to $60 \% \mathrm{O}_{2}$ (Fig. 9), relative to air-exposed groups. This increase in expression was attenuated by treatment with SB217242.

\section{DISCUSSION}

In this study, we examined the proliferative and antiapoptotic effects of ET-1 on pulmonary arterial smooth muscle to understand the mechanisms by which ET-1 influences vascular smooth muscle hyperplasia in newborn rats. Our in 

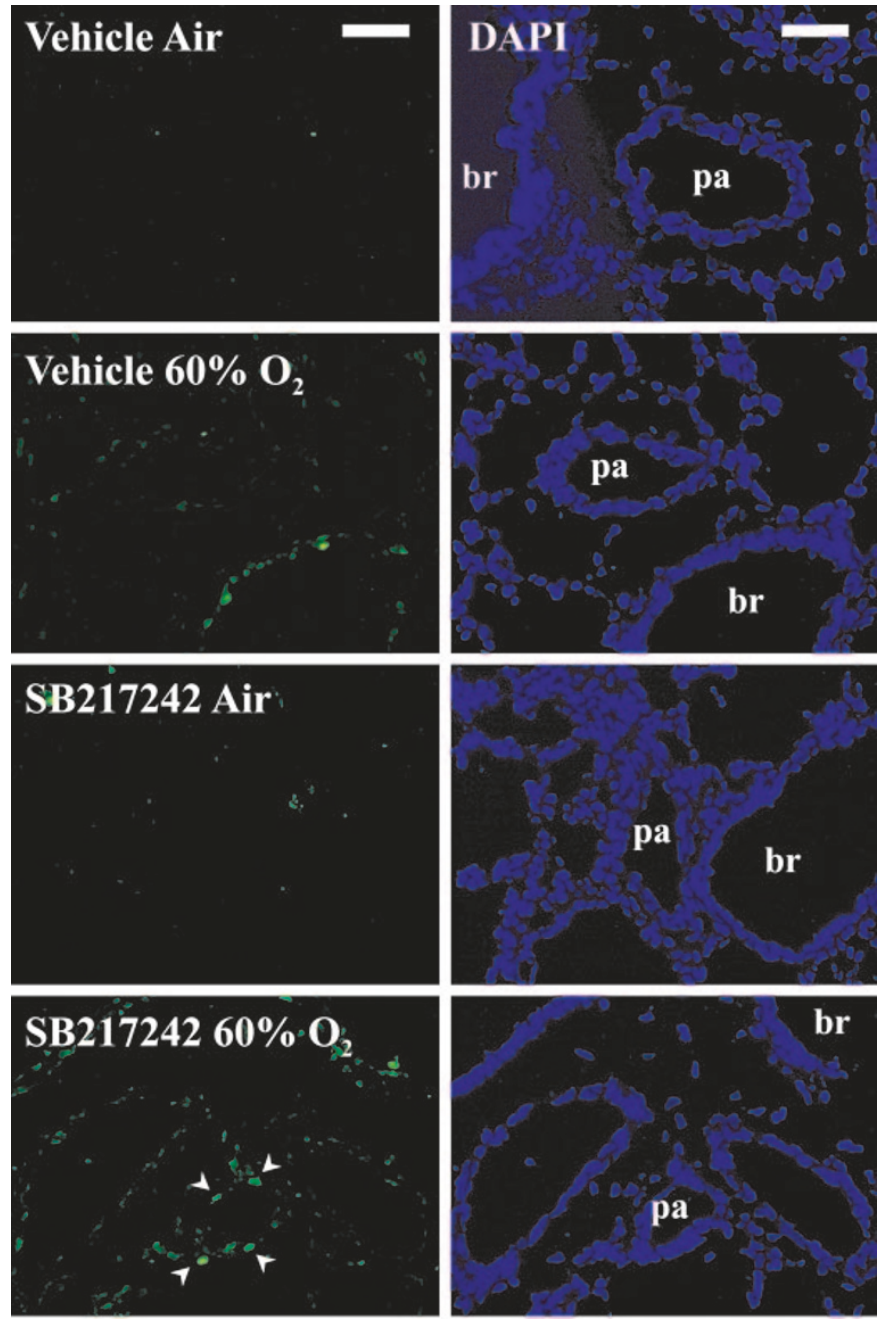

Figure 6. SB217242 increases smooth muscle apoptosis in $60 \% \mathrm{O}_{2}$-exposed animals. Representative images of in situ TUNEL (green fluorescence) on frozen lung tissue sections from rat pups exposed from birth to either air or $60 \% \mathrm{O}_{2}$ and receiving either vehicle or SB217242. Right-hand panels show corresponding DAPI-stained sections (violet fluorescence) identifying pulmonary arteries (pa) and their corresponding bronchi (br). Bar lengths $=50 \mu \mathrm{m}$.

vitro findings were that ET-1 did not directly stimulate PASMC proliferation, even under hyperoxic conditions, but did have major inhibitory influences on apoptosis and expression of the pro-apoptotic factor, Bax. Our in vivo findings were that chronic hyperoxia increased vascular smooth muscle proliferation, lung expression of ET-1 and vascular wall expression of $\mathrm{ET}_{\mathrm{A}} \mathrm{R}$. Hyperoxia also increased vascular wall expression of the anti-apoptotic factor, Bcl-xL, and decreased the expression of Bax. Endothelin receptor blockade with the combined $\left(\mathrm{ET}_{\mathrm{A}} \mathrm{R} / \mathrm{ET}_{\mathrm{B}} \mathrm{R}\right)$ antagonist, $\mathrm{SB} 217242$, abrogated these hyperoxia-induced changes and led to increased numbers of TUNEL-positive cells in the medial vascular wall. We also observed increased $\mathrm{ET}_{\mathrm{A}} \mathrm{R}$ expression in the vessels of both air- and $60 \% \mathrm{O}_{2}$-exposed SB217242-treated animals, which we speculate was related to compensatory upregulation in response to receptor blockade. Taken together, our findings are consistent with an important role for ET-1 as a survival and anti-apoptotic factor for newborn rat pulmonary vascular smooth muscle, both in vitro and in vivo.

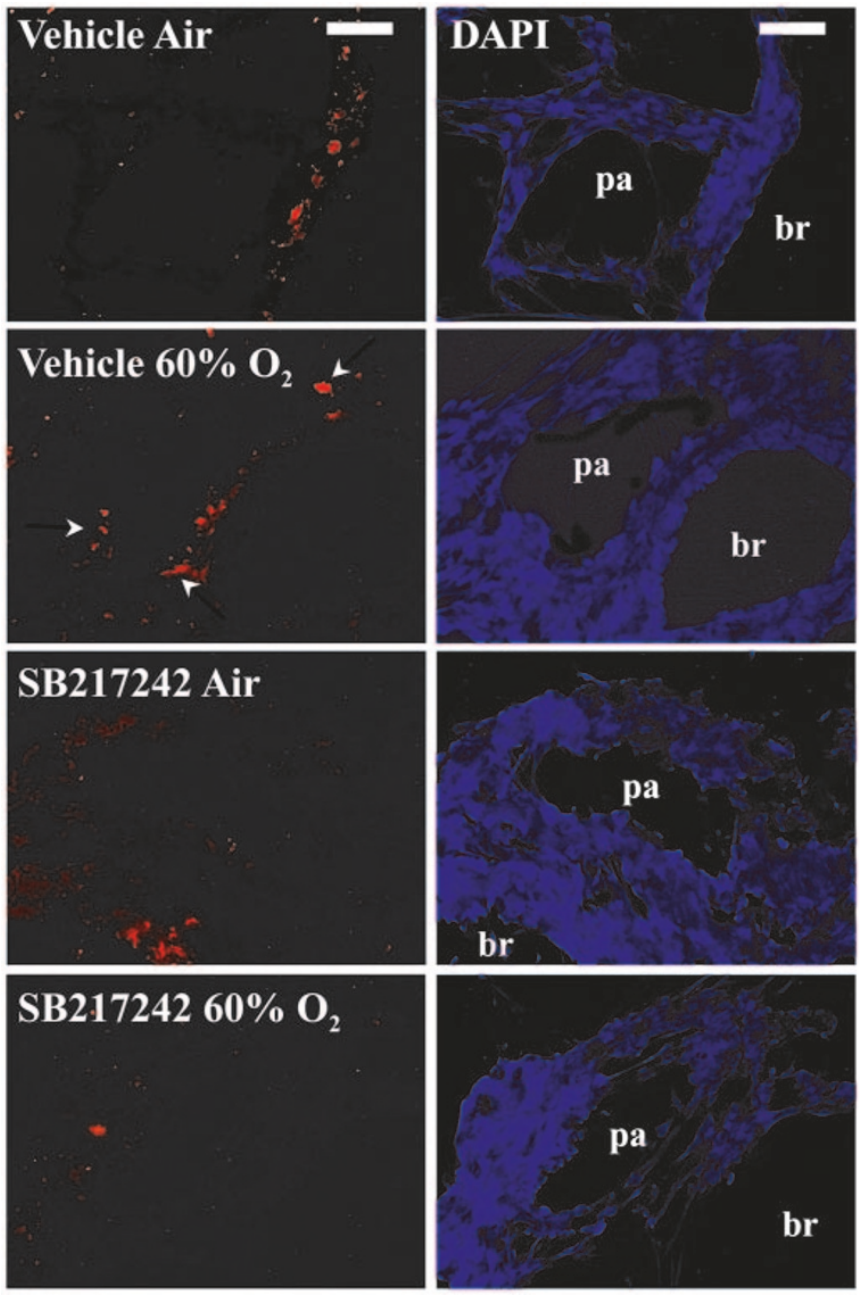

Figure 7. SB217242 prevents increased smooth muscle proliferation in $60 \%$ $\mathrm{O}_{2}$-exposed animals. Representative images of BrdU-positive nuclei (red fluorescence) on frozen lung tissue sections from rat pups exposed from birth to either air or $60 \% \mathrm{O}_{2}$ and receiving either vehicle or SB217242. Right hand panels show corresponding DAPI-stained sections (violet fluorescence) identifying pulmonary arteries (pa) and their corresponding bronchi (br). Bar lengths $=50 \mu \mathrm{m}$.

Our in vitro observations are at odds with the finding that ET receptor blockade inhibited arterial smooth muscle proliferation in hyperoxia-exposed animals. They also differ from the reports of others demonstrating, albeit modest, mitogenic properties for ET-1 alone on PASMCs derived from adult rats (25) and fetal lambs (26) and much more potent mitogenic effects on systemic vascular SMCs in the presence of PDGFs (27). The negative findings in our study are unlikely to have been explained by the concentrations used being either above or below the threshold of response, as we used a wide range of concentrations encompassing those reported to be effective by others, nor could they be explained by toxicity. We have recently reported that increased arterial smooth muscle proliferation in pulmonary resistance arteries of $60 \% \mathrm{O}_{2}$-exposed newborn rats resulted from ET receptor-mediated upregulation of the activated PDGF $\beta$-receptor (22). While it remains possible that ET-1 may play a direct role in stimulating smooth muscle proliferation in vivo, we interpret our 

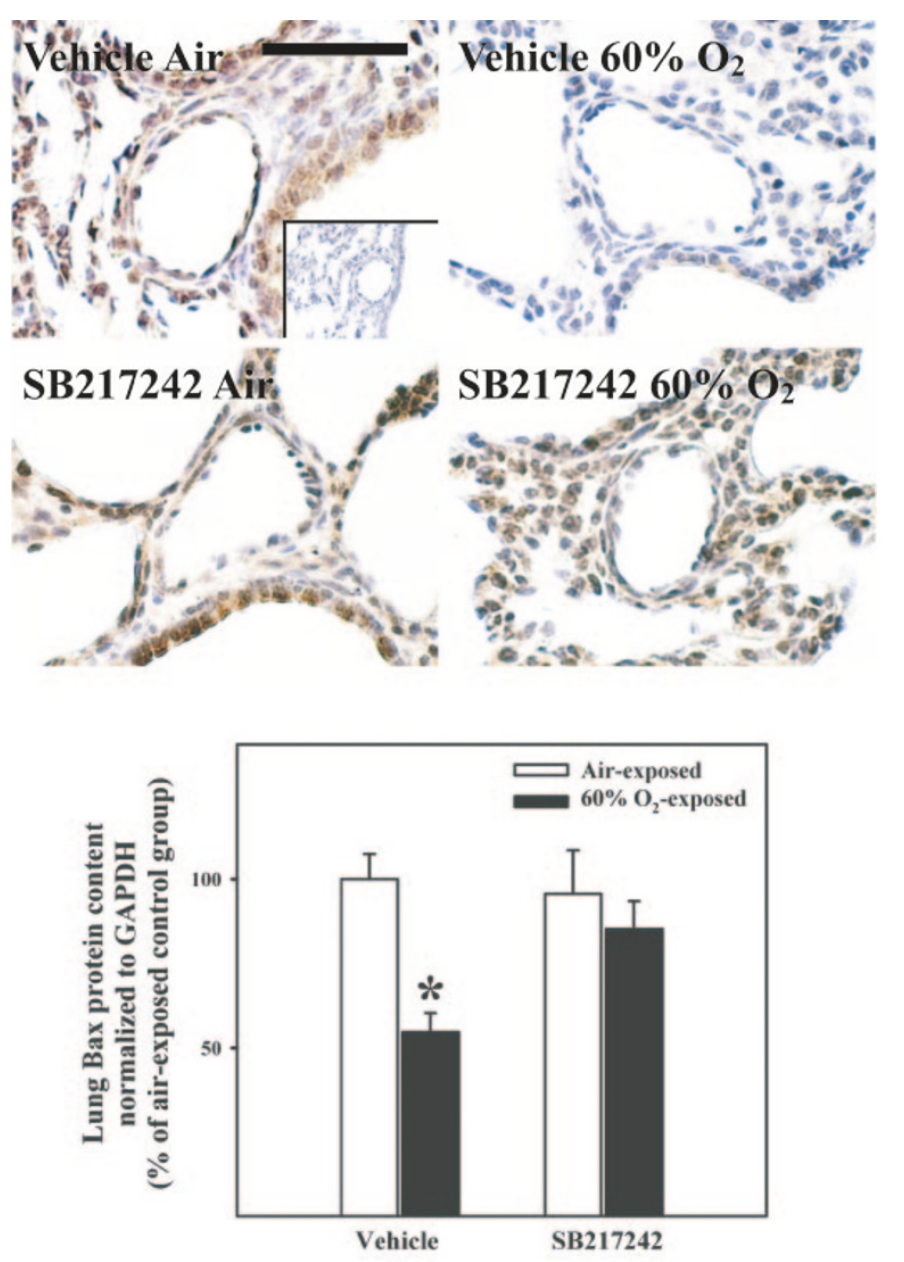

Figure 8. Exposure to $60 \% \mathrm{O}_{2}$ decreases Bax expression. Upper panel: Representative photomicrographs of immunoreactive Bax (brown stain) in rat pups exposed from birth to either air or $60 \% \mathrm{O}_{2}$ and receiving either vehicle or SB217242. Bar length $=50 \mu \mathrm{m}$. Inset: negative control demonstrating complete lack of staining. Lower panel: Western blot analyses of total lung Bax protein content, normalized to GAPDH. ${ }^{*} p<0.05$, by ANOVA, compared with all other groups.

current and previous (22) findings as consistent with ET-1 acting both as an indirect mitogen of pulmonary artery smooth muscle (through PDGF $\beta$-receptor signaling) and as a direct survival and anti-apoptotic factor. Other mechanisms by which ET-1 may contribute to smooth muscle growth, not explored in this study, include the induction of hypertrophy through increased protein synthesis and changes in composition of the extracellular matrix, which are also believed to play important roles in the pathogenesis of vascular remodeling (8). Furthermore, our present findings do not rule out the potential for important proliferative properties of ET-1 on other vascular cell types involved in remodeling, such as adventitial fibroblasts (28).

ET-1 has been shown to rescue a number of cell types from apoptosis-inducing stimuli including paclitaxel (18), nitric oxide (29), or serum deprivation (30). Although others have demonstrated that ET-1 has anti-apoptotic effects on systemic vascular SMCs, through $\mathrm{ET}_{\mathrm{A}} \mathrm{R}$ stimulation (18), this is the first study, to our knowledge, to examine the effects of ET-1

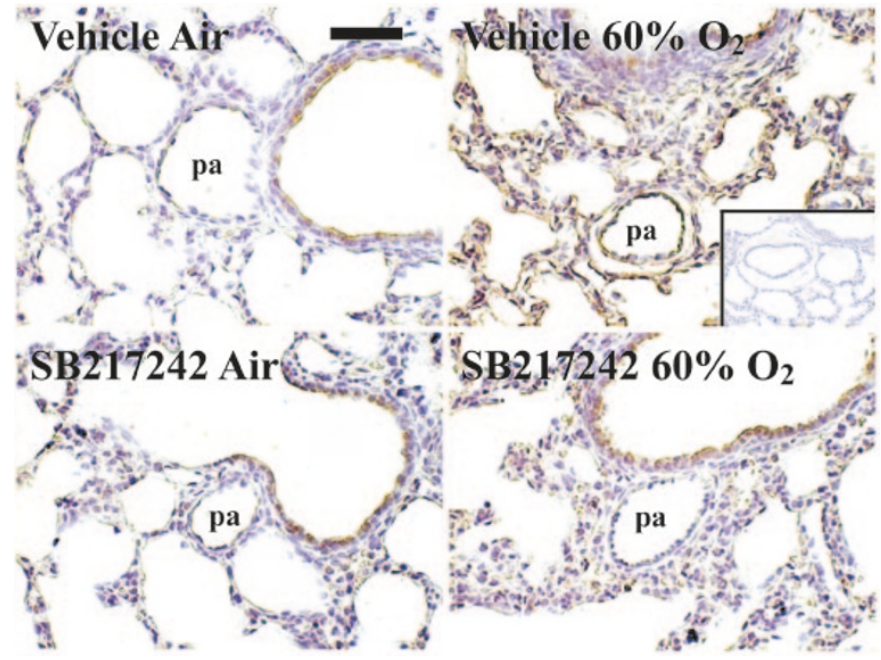

Figure 9. Exposure to $60 \% \mathrm{O}_{2}$ increases Bcl-xL expression. Representative photomicrographs of immunoreactive $\mathrm{Bcl}-\mathrm{xL}$ (brown stain) on pulmonary arteries (PA) of rat pups exposed from birth to either air or $60 \% \mathrm{O}_{2}$ and receiving either vehicle or SB217242. Bar length $=50 \mu \mathrm{m}$. Inset: negative control demonstrating complete lack of staining.

on apoptosis of pulmonary vascular smooth muscle. The mechanism/s by which ET-1 modulates apoptosis in SMCs have yet to be fully explored. Studies performed on other cell types have implicated ET-1-induced generation of reactive oxygen species (31), mitogen-activated protein kinase (29) or Akt activation (32) and changes in expression of intracellular regulators of apoptosis, such pro-apoptotic Bax (33) and anti-apoptotic Bcl-2 family members (32) including changes in their respective ratios favoring inhibition of apoptosis (31). Our present in vivo observations argue against a major role for down-regulation of Bax alone in mediating the anti-apoptotic effects of ET-1. However, they are consistent with an alteration in the ratio of $\mathrm{Bax}$ to $\mathrm{Bcl}-\mathrm{xL}$ (or other $\mathrm{Bcl}-2$ family members) possibly playing an important role.

In conclusion, our observations suggest that ET-1 is an important survival and anti-apoptotic factor for neonatal rat pulmonary arterial smooth muscle, which may at least partly account for the reported efficacy of ET receptor antagonists in the prevention and treatment of pulmonary vascular remodeling in newborn animals $(10,11)$.

\section{REFERENCES}

1. Walsh MC, Stork EK 2001 Persistent pulmonary hypertension of the newborn. Rational therapy based on pathophysiology. Clin Perinatol 28:609-627

2. Jeffery TK, Wanstall JC 2001 Pulmonary vascular remodeling: a target for therapeutic intervention in pulmonary hypertension. Pharmacol Ther 92:1-20

3. Durmowicz AG, Stenmark KR 1999 Mechanisms of structural remodeling in chronic pulmonary hypertension. Pediatr Rev 20:E91-E102

4. Belik J, Jankov RP, Pan J, Tanswell AK 2003 Chronic $\mathrm{O}_{2}$ exposure enhances vascular and airway smooth muscle contraction in the newborn but not adult rat. J Appl Physiol 94:2303-2312

5. Todd L, Mullen M, Olley PM, Rabinovitch M 1985 Pulmonary toxicity of monocrotaline differs at critical periods of lung development. Pediatr Res 19:731-737

6. Ladha F, Bonnet S, Eaton F, Hashimoto K, Korbutt G, Thebaud B 2005 Sildenafil improves alveolar growth and pulmonary hypertension in hyperoxia-induced lung injury. Am J Respir Crit Care Med 172:750-756

7. Geraci MW, Moore M, Gesell T, Yeager ME, Alger L, Golpon H, Gao B, Loyd JE, Tuder RM, Voelkel NF 2001 Gene expression patterns in the lungs of patients with primary pulmonary hypertension: a gene microarray analysis. Circ Res 88:555-562

8. Jeffery TK, Morrell NW 2002 Molecular and cellular basis of pulmonary vascular remodeling in pulmonary hypertension. Prog Cardiovasc Dis 45:173-202 
9. McMurtry MS, Bonnet S, Wu X, Dyck JR, Haromy A, Hashimoto K, Michelakis ED 2004 Dichloroacetate prevents and reverses pulmonary hypertension by inducing pulmonary artery smooth muscle cell apoptosis. Circ Res 95:830-840

10. Jankov RP, Luo X, Belcastro R, Copland I, Frndova H, Lye SJ, Hoidal JR, Post M, Tanswell AK 2001 Gadolinium chloride inhibits pulmonary macrophage influx and prevents $\mathrm{O}_{2}$-induced pulmonary hypertension in the neonatal rat. Pediatr Res 50:172-183

11. Ambalavanan N, Bulger A, Murphy-Ullrich J, Oparil S, Chen YF 2005 Endothelin-A receptor blockade prevents and partially reverses neonatal hypoxic pulmonary vascular remodeling. Pediatr Res 57:631-636

12. Rosenberg AA, Kennaugh J, Koppenhafer SL, Loomis M, Chatfield BA, Abman SH 1993 Elevated immunoreactive endothelin-1 levels in newborn infants with persistent pulmonary hypertension. J Pediatr 123:109-114

13. Niu JO, Munshi UK, Siddiq MM, Parton LA 1998 Early increase in endothelin-1 in tracheal aspirates of preterm infants: correlation with bronchopulmonary dysplasia. J Pediatr 132:965-970

14. Zamora MA, Dempsey EC, Walchak SJ, Stelzner TJ 1993 BQ123, an ETA receptor antagonist, inhibits endothelin-1-mediated proliferation of human pulmonary artery smooth muscle cells. Am J Respir Cell Mol Biol 9:429-433

15. Hahn AW, Resink TJ, Scott-Burden T, Powell J, Dohi Y, Buhler FR 1990 Stimulation of endothelin mRNA and secretion in rat vascular smooth muscle cells: a novel autocrine function. Cell Regul 1:649-659

16. Shichiri M, Kato H, Marumo F, Hirata Y 1997 Endothelin-1 as an autocrine/ paracrine apoptosis survival factor for endothelial cells. Hypertension 30:1198-1203

17. Shichiri M, Sedivy JM, Marumo F, Hirata Y 1998 Endothelin-1 is a potent survival factor for c-Myc-dependent apoptosis. Mol Endocrinol 12:172-180

18. Wu-Wong JR, Chiou WJ, Dickinson R, Opgenorth TJ 1997 Endothelin attenuates apoptosis in human smooth muscle cells. Biochem J 328:733-737

19. Dempsey EC, Badesch DB, Dobyns EL, Stenmark KR 1994 Enhanced growth capacity of neonatal pulmonary artery smooth muscle cells in vitro: dependence on cell size, time from birth, insulin-like growth factor I, and auto-activation of protein kinase C. J Cell Physiol 160:469-481

20. Jankov RP, Luo X, Cabacungan J, Belcastro R, Frndova H, Lye SJ, Tanswell AK 2000 Endothelin- 1 and $\mathrm{O}_{2}$-mediated pulmonary hypertension in neonatal rats: a role for products of lipid peroxidation. Pediatr Res 48:289-298

21. Koppel R, Han RN, Cox D, Tanswell AK, Rabinovitch M $1994 \alpha 1$-antitrypsin protects neonatal rats from pulmonary vascular and parenchymal effects of oxygen toxicity. Pediatr Res 36:763-770

22. Jankov RP, Kantores C, Belcastro R, Yi S, Ridsdale RA, Post M, Tanswell AK 2005 A role for platelet-derived growth factor $\beta$-receptor in a newborn rat model of endothelin-mediated pulmonary vascular remodeling. Am J Physiol Lung Cell Mol Physiol 288:L1162-L1170

23. Tanswell AK, Fraher LJ, Grose EC 1989 Circulating factors that modify lung cell DNA synthesis following exposure to inhaled oxidants. I.Effect of serum and lavage on lung fibroblasts following exposure of adult rats to $1 \mathrm{ppm}$ ozone. J Toxicol Environ Health 27:239-254

24. Shirhatti V, Krishna G 1985 A simple and sensitive method for monitoring druginduced cell injury in cultured cells. Anal Biochem 147:410-418

25. Zamora MR, Stelzner TJ, Webb S, Panos RJ, Ruff LJ, Dempsey EC 1996 Overexpression of endothelin-1 and enhanced growth of pulmonary artery smooth muscle cells from fawn-hooded rats. Am J Physiol 270:L101-L109

26. Wedgwood S, Dettman RW, Black SM 2001 ET-1 stimulates pulmonary arteria smooth muscle cell proliferation via induction of reactive oxygen species. Am J Physiol Lung Cell Mol Physiol 281:L1058-L1067

27. Weissberg PL, Witchell C, Davenport AP, Hesketh TR, Metcalfe JC 1990 The endothelin peptides ET-1, ET-2, ET-3 and sarafotoxin S6b are co-mitogenic with platelet-derived growth factor for vascular smooth muscle cells. Atherosclerosis 85:257-262

28. Stenmark KR, Bouchey D, Nemenoff R, Dempsey EC, Das M 2000 Hypoxiainduced pulmonary vascular remodeling: contribution of the adventitial fibroblasts. Physiol Res 49:503-517

29. Shichiri M, Yokokura M, Marumo F, Hirata Y 2000 Endothelin-1 inhibits apoptosis of vascular smooth muscle cells induced by nitric oxide and serum deprivation via MAP kinase pathway. Arterioscler Thromb Vasc Biol 20:989-997

30. Del Bufalo D, Di Castro V, Biroccio A, Salani D, Rosano L, Spinella F, Bagnato A 2002 Endothelin-1 acts as a survival factor in ovarian carcinoma cells. Clin Sci (Lond). 103:S302-S305.

31. Dong F, Zhang X, Wold LE, Ren Q, Zhang Z, Ren J 2005 Endothelin-1 enhances oxidative stress, cell proliferation and reduces apoptosis in human umbilical vein endothelial cells: role of $\mathrm{ET}_{\mathrm{B}}$ receptor, NADPH oxidase and caveolin-1. Br J Pharmacol 145:323-333

32. Del Bufalo D, Di Castro V, Biroccio A, Varmi M, Salani D, Rosano L, Trisciuoglio D, Spinella F, Bagnato A 2002 Endothelin-1 protects ovarian carcinoma cells agains paclitaxel-induced apoptosis: requirement for Akt activation. Mol Pharmacol 61:524-532

33. Srivastava RK, Srivastava AR, Korsmeyer SJ, Nesterova M, Cho-Chung YS, Longo DL 1998 Involvement of microtubules in the regulation of Bcl2 phosphorylation and apoptosis through cyclic AMP-dependent protein kinase. Mol Cell Biol 18:3509-3517 